\title{
Extra-anatomical Cephalic to Internal Jugular Vein Bypass for Central Venous Occlusion
}

\author{
Zia Ur Rehman \\ Department of Surgery, The Aga Khan University Hospital, Karachi, Pakistan
}

\begin{abstract}
Extra-anatomical cephalic to internal jugular venovenous bypass is a surgical method of improving the patency of arteriovenous access in patients with central venous stenosis (CVS), which is infrequently performed. It can be more durable compared to percutaneous venoplasty for CVS. We present a 60 -year male who developed right subclavian vein stenosis after brachiocephalic arteriovenous fistula. He had two sessions of venoplasty, but had recurrence. Later, his CVS lesion was not amenable to venoplasty. He underwent cephalic to internal jugular venovenous bypass with externally supported polytetrafluoroethylene (PTFE) graft. This provided immediate symptomatic relief and also salvaged his fistula, which was patent at his last follow-up visit at six months. Venovenous bypass can be considered earlier in 'selected' patients to deal CVS not amenable to percutaneous interventions.
\end{abstract}

Key Words: Arteriovenous fistula, Extra-anatomical bypass, Central venous stenosis.

How to cite this article: Rehman ZU. Extra-anatomical cephalic to internal jugular vein bypass for central venous occlusion. $J$ Coll Physicians Surg Pak 2020; 30(2):219-221.

\section{INTRODUCTION}

Native arteriovenous fistula (AVF) is the best form of haemodialysis access as having better patency and lesser infectious complications compared to arteriovenous grafts and dialysis catheters. Central venous stenosis (CVS) is one of the long-term complications of access creation. It occurs in $16 \%-27 \%$ in patients on haemodialysis. ${ }^{1}$ Patients who have history of central vein cannulation or arteriovenous access on the ipsilateral arm are at risk of developing this condition. ${ }^{2}$ The catheter causes intimal damage and neo-intimal formation. Percutaneous venoplasty to treat this condition itself causes intimal damage and is a risk factor for CVS.

Patients with CVS present with ipsilateral arm, neck and breast swelling and have dysfunctional arteriovenous accesses. Patients complain of prolonged bleeding after removal of dialysis needles.

Percutaneous angioplasty is although a minimal, invasive method of treating CVS, but its effect is short-lived and repeat angioplasty is a norm. ${ }^{3}$ In patients where venoplasty is not possible or has failed, options left are either the ligation of (AVF) or to perform a surgical bypass. Ligation of AVF, although a simple solution for relieving arm swelling, is at the cost of access loss, which in these patients is considered as 'life-line'. The

Correspondence to: Dr. Zia Ur Rehman, Section of Vascular Surgery, Department of Surgery, The Aga Khan University

Hospital, Karachi, Pakistan

E-mail: ziaur.rehman@aku.edu

Received: May 24, 2019; Revised: July 24, 2019;

Accepted: August 08, 2019 pre-requisite for surgical bypass is to have patent outflow vein.

Extra-anatomical cephalic to internal jugular vein (IJV) venovenous bypass is one of the surgical bypasses in patients who have patent IJV. This may be considered in patients with dysfunctional brachiocephalic AVF due to CVS. We report a patient with poorly functioning brachiocephalic AVF who had complete subclavian vein occlusion and successfully underwent this bypass.

\section{CASE REPORT}

A 60-year male, diabetic, hypertensive, chronic renal failure patient on regular dialysis had right brachiocephalic AVF created in November 2017. He had no history of central venous cannulation. He was having persistent arm swelling; and his upper arm venogram showed severe subclavian vein stenosis. It was causing more than $70 \%$ stenosis. He underwent balloon angioplasty in July 2018 with $10 \times 40 \mathrm{~mm}$ balloon. His arm swelling partially decreased after venoplasty. Within 3 months, he developed recurrent symptoms and recurrent stenosis. He had second session of venoplasty, which was effective in relieving symptoms for next two months. He again developed arm swelling, which was three times than the contralateral normal side. It was severely affecting his quality of life. Current venogram showed complete sub-clavian vein occlusion (Figure 1). Venoplasty was attempted but guidewire was not negotiable across the lesion. The patency of right IJV was checked by performing venogram; and it was patent.

Patient was counselled about the risks and benefits for surgical options, for which he consented. Extra- 


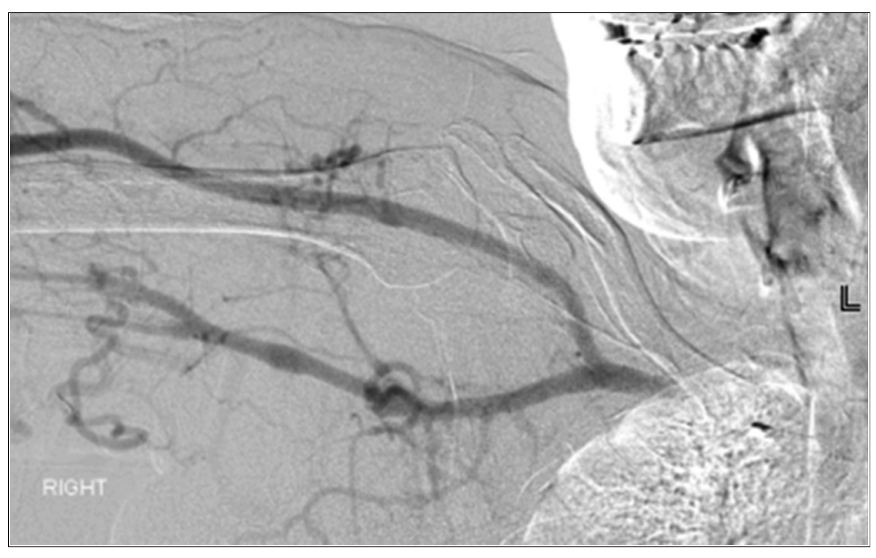

Figure 1: Venogram showing complete subclavian vein occlusion (arrow).

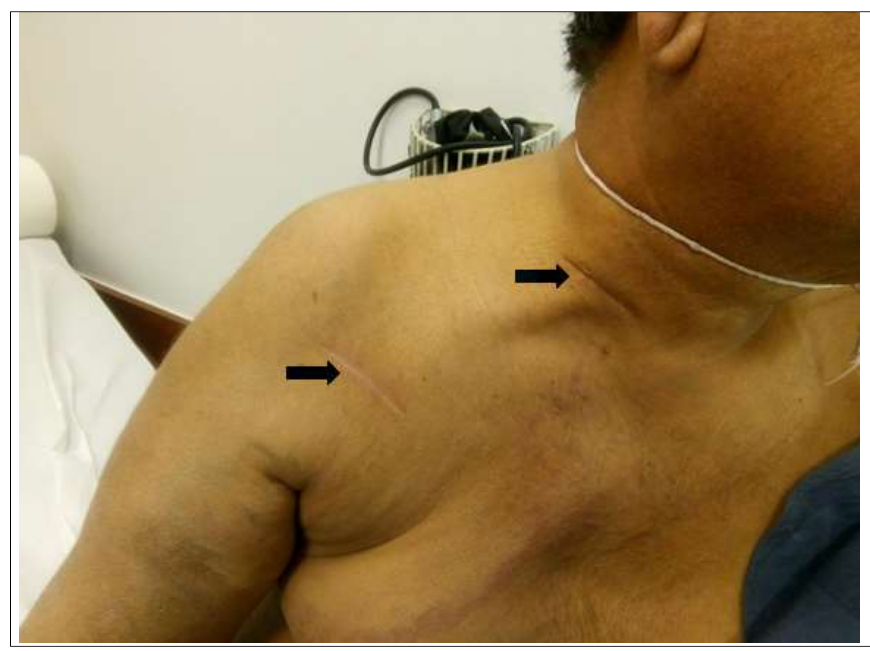

Figure 2: Showing postoperative incisional scar marks: Cephalic vein dissection in the upper arm and right internal jugular vein in lower neck. Graft is running in between the two veins.

anatomical cephalic to IJV bypass was planned in January 2019. Under general anaesthesia, proximal cephalic vein was exposed in upper arm while right IJV was dissected through low neck incision. Both were done through transverse incisions. IJV was exposed by splitting the lower-most fibers of sternocleidomastoid muscle. Subcutaneous tunnel was created between cephalic vein to IJV and externally supported PTFE $8 \mathrm{~mm}$ graft was placed. End-to-side anastomoses were created between graft and veins, and flow was established.

Patient had palpable thrill in the access and his arm oedema settled completely. Fistula was useable for immediate next dialysis. He had smooth recovery. On his last follow-up visit at six months, he was symptomfree with patent graft (Figure 2).

\section{DISCUSSION}

In the present case, patient tolerated extra-anatomical veno-venous bypass quite well with symptomatic improvement. Selvanathan et al. also reported efficacy of venovenous bypass for salvaging functioning ipsilateral fistula threatened by occluded upper central vein with 12 months patency of $80 \% .{ }^{4}$ All patients had longer bypass as none of the patients, in this series, had IJV as outflow vessel. It was occluded due to previous central line placements. In this case, patient was fortunate to have patent IJV. He had a shorter bypass compared to cephalic to femoral venovenous bypasses used in that series.

Although invasive, surgical bypasses are more durable than venoplasties. In a 12-month follow-up, patients who underwent surgical bypass had $75 \%$ versus $63 \%$ patency rate than those treated with angioplasty. ${ }^{5}$

IJV transposition for subclavian vein stenosis has also been reported for relieving symptoms of CVS.6,7 We used PTFE graft as it shortened operating time and also avoided extensive neck dissection. Same approach had been reported by Suliman et al. in relieving CVS symptoms. ${ }^{8}$

More cases of cephalic to IJV venovenous bypasses with long term follow-up may establish their role well in the algorithm for managing patients with CVS.

Extra-anatomical cephalic to IJV venovenous bypass for a patient with subclavian vein occlusion improved patency of arm AVF and relieved arm swelling significantly. Patient did not develop recurrent symptoms.

\section{PATIENT'S CONSENT:}

Informed consent was obtained from patient to publish data concerning this case.

\section{CONFLICT OF INTEREST:}

Authors declared no conflict of interest.

\section{AUTHOR'S CONTRIBUTION:}

ZUR: Concept of the study, data collection and interpretation, manuscript writing, revision, critical review, final approval and accountability of all aspects of the work.

\section{REFERENCES}

1. Cuthbert GA, Lo ZJ, Kwan J, Chandrasekar S, Tan GWL. Outcomes of central venoplasty in hemodialysis patients. Ann Vasc Dis 2018; 11:292-7.

2. Bhadauria D, Chellappan A, Gurjar M, Kaul A, Sharma RK, Prasad N. The "dilemma of double lifelines": Central venous catheter co-existence with transvenous cardiac pacemaker. $J$ Vasc Access 2017; 18:e 3-5.

3. Aj A, Razak Uk A, R P, Pai U, M S. Percutaneous intervention for symptomatic central vein stenosis in patients with upper limb arteriovenous dialysis access. Indian Heart $J$ 2018; 70: 690-8.

4. Selvanathan SK, Azizi ZA. Extra-anatomical veno-venous surgical bypass for central vein occlusion in patients with ipsilateral arterio-venous fistula (AVF) for hemodialysis - A single centre experience. Med J Malaysia 2017; 1:3-6. 
5. Dammers R, De Haan MW, Planken NR, van der Sande FM, Tordoir JH. Central vein obstruction in hemodialysis pateints: Results of radiological and surgical interventions. J Vasc Surg 2007; 45:776-83.

6. Puskas JD, Gertlas JP. Internal jugular to axillary vein bypass for subclavian vein thrombosis in the setting of brachial arteriovenous fistula. J Vasc Surg 1994; 19:939-42.
7. Bachleda P, Utikal P, Kocher M, Zadrazil J. Contribution of the corrections of central venous hypertension after the creation of an arteriovenous (AV) fistula for hemodialysis. Acta Univ Palacki Olomuc Fac Med 1999; 142:111-4.

8. Suliman A, Greenberg JI, Angle N. Surgical bypass for symptomatic central venous obstruction for arteriovenous fistula salvage in hemodialysis patients. Ann Surg 2008; 22; 203-9.

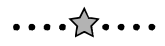

